\title{
Hyperimmunoglobulin E syndrome associated with nephrotic syndrome-case report
}

\begin{abstract}
Hyper IgE syndrome is a rare primary immunodeficiency disease characterized by pruritic dermatitis, recurrent cutaneous abscesses, recurrent sinopulmonary infections and extremely elevated levels of IgE in serum. Although various systemic findings have been identified in hyper-IgE syndome, renal disease is rarely associated with it. Here we report a rare case of a three years old child with hyper-IgE syndrome who had developed nephrotic syndrome.
\end{abstract}

Keywords: otitis media, mucocutaneous candidiasis, spongiosis, perivascular dermatitis
Volume 4 Issue 6 - 2020

\author{
Safa Elfaituri,' Idris Matoug, ${ }^{2}$ Noureddine \\ Cherif, ${ }^{3}$ Mourad Mokni ${ }^{4}$ \\ 'Department of Dermatology, Faculty of Medicine, Benghazi \\ University, Libya \\ ${ }^{2}$ Department of Pediatric, Faculty of Medicine, Benghazi \\ University, Libya \\ ${ }^{3}$ El Farabi medical centre, Tunisia \\ ${ }^{4}$ Mourad Mokni, La Rabta Hospital, Tunisia
}

Correspondence: Safa Elfaituri, Department of Dermatology, Faculty of Medicine, Benghazi University, Libya, Email selfaioury@yahoo.co.uk

Received: November 21, 2020 | Published: November 30, 2020

\section{Case report}

A 3 years old child with coarse facial appearance was suffered from generalized eczema associated with secondary infections and recurrent multiple skin abscesses since he was 1 year old. The dermatitis and infections was present to some degree at all times. The patient had wheezy chest, food (cow milk) allergy and recurrent attacks of otitis media, candidiasis and herpes simplex virus infection with Kaposi varicelliform eruption. There was positive consanguinity between parents and positive family history with his older brother -5 years old, had similar disease. Routine blood counts revealed leukocytosis with persistent eosinophilia (40\%). Blood chemistry was normal. The serum IgE level was11.000IU/ml with normal levels of other immunoglobulin classes.

Radiological findings revealed no abnormality in the bone. H\&E stained histological sections of skin biopsy revealed spongiosis and perivascular dermatitis with a preponderance of eosinophils. At 3 years of age he developed generalized swelling, involving face especially periorbital regions, scrotum, abdomen and lower extremities.

The patient was irritable, Tachypnic with severe pitting edema in both lower extremities, His blood pressure was normal and his urinalysis revealed a proteinuria of $3+$.

Further laboratory investigation showed significant hypoproteinemia and hypoalbuminemia with total protein level of $3.6 \mathrm{~g} / \mathrm{dL}$ and albumin level of $1.5 \mathrm{~g} / \mathrm{dL}$, the urine protein-to-creatinine ratio was 4.16 whereas his serum electrolytes, creatinine and BUN were normal, which are all compatible with nephrotic syndrome. Renal ultrasonography and Doppler disclosed no abnormalities. Lipid profile (cholesterol and triglyceride) and complement studies (C3, C4) levels were normal. HIV, HCV, HBsAg were negative. Antinuclear antibody was negative. Treatment was started with oral prednisone $30 \mathrm{mg} /$ day and complete resolution of proteinuria occurred within 1 month of steroid therapy without relapse within 1 year (Figure 1-2).

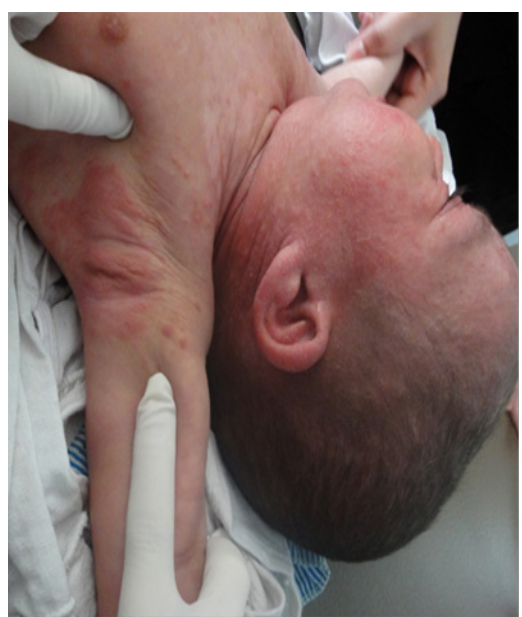

Figure I Eczematous rash at I years old.

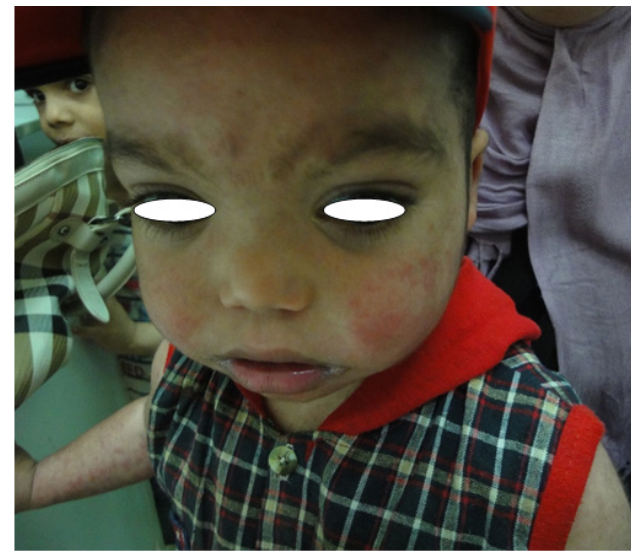

Figure 2 Coarse facial features. 


\section{Discussion}

Our patient had typical presentation of Hyper IgE syndrome with early onsets ever and recal citrant dermatitis associated with secondary bacterial infection, recurrent chest infection, skin abscesses and mucocutaneous candidiasis. Because of positive consanguinity and family history, the associated recurrent sever viral infection, chest allergy as well as food allergy we think that our patient has autosomal recessive hyper Ig E syndrome. The two most consistent laboratory findings of HIES are elevated serum IgE level and eosinophilia. The serum IgE typically peaks above $2000 \mathrm{IU} / \mathrm{mL}$. Although both atopic dermatitis and food allergies can result in skin rash, eosinophilia and elevated serum IgE, an extremly higher level $>2000 \mathrm{IU} / \mathrm{mL}$ is characteristic for in HIGE. Our patient had extremely high IgE) 11.000 $\mathrm{IU} / \mathrm{ml}\left(\right.$ and eosinophilia $(40 \%) \cdot{ }^{1-5}$

Nephrotic syndrome is a kidney disorder characterized by proteinuria, hypoalbuminemia and edema and in some cases, there is high cholesterol and a predisposition for coagulation. The cause is damage to the glomeruli leading to an increase in permeability of the capillary walls of the glomerulus.

In children it is defined as protein excretion of more than $40 \mathrm{mg} /$ $\mathrm{m} 2 / \mathrm{h}$ or a first-morning urine protein/creatinine of $2-3 \mathrm{mg} / \mathrm{mg}$ creatinine or greater.

Our patient developed clinical and laboratory features of nephrotic syndrome, lipid profile, complement studies and serology were negative excluding secondary nephrotic. Patients suffering from nephrotic syndrome have a good prognosis under steroid treatment with a minimum total duration of treatment of 12 weeks, our patient was responded to steroid therapy within few weeks; the steroid therapy decreased urinary protein loss and hypoproteinemia, and his pruritic skin rash was also improved.

Association of HIES with nephrotic syndrome has been reported. Recurrent infection in hyprIgE syndrome, especially staphylococcus aureus infections lead to continuous antigen stimulation which may cause renal immune complex damage.
In conclusion we report a rare case of hyprIgE syndrome associated with nephrotic syndrome; hyprIgE syndrome is a primary immune deficiency disease with recurrent infection and continuous antigen stimulation which may cause glomeruli immune complex damage and nephrotic syndrome.

\section{Funding}

None.

\section{Conflicts of interest}

We declare no conflicts of interest.

\section{Acknowledgments}

None.

\section{References}

1. Szczawinska-Poplonyk A, Kycler Z, Pietrucha B, et al. The hyperimmunoglobulin E syndrome - clinical manifestation diversity in primary immune deficiency. Orphanet Journal of Rare Diseases. 2011, 6:76.

2. Sepet E, Ozdemir D, Aksakalli N, et al. Hyper-IgE syndrome: a case report . J Clin Pediatr Dent. 2001;25(4):333-336.

3. Miyazaki K, Miyazawa T, Sugimoto K, et al. An adolescent with marked hyperimmuno-globulinemia $\mathrm{E}$ showing minimal change nephrotic syndrome and a STAT3 gene mutation. Clin Nephrol. 2011;75(4):369373.

4. Bong $\mathrm{C}-\mathrm{N}$, Huang $\mathrm{S}-\mathrm{C}$, Wang $\mathrm{C}-\mathrm{L}$. Cyclosporin A therapy in a case with hyperimmunoglobulin $\mathrm{E}$ and nephrotic syndrome. J Microbiol Immunol Infect. 2005;38(1):60-64.

5. Tanji C, Yorioka N, Kanahara K, et al. Hyperimmunoglobulin E syndrome associated withnephrotic syndrome. Intern Med. 1999;38(6):491-494. 